\title{
Instant messaging apps and data protection: combining to improve hip fracture care?
}

\author{
Geoff Crozier-Shaw $^{1,3}$ (D) Andrew J. Hughes ${ }^{1,3} \cdot$ James Cashman ${ }^{1,2,3} \cdot$ Keith Synnott $^{1,2,3}$
}

Received: 27 January 2021 / Accepted: 28 March 2021 / Published online: 5 April 2021

(c) Royal Academy of Medicine in Ireland 2021

\begin{abstract}
Introduction The General Data Protection Regulation (GDPR) continues to have implications for how healthcare information is managed and shared. This presents challenges as telemedicine plays a more central role in service healthcare service provision, particularly since the beginning of 2020 . We aim to measure how improved communication through a GDPR-compliant messaging app can influence time-dependent key performance indicators for hip fracture management in a tertiary-referral trauma hospital. Methods Using an instant messaging service, a hip fracture group was created and access was provided to all stakeholders in hip fracture care - trainee and consultant emergency physicians and orthopaedic surgeons, as well as advanced nurse practitioners, bed managers, ward managers and theatre managers. Irish Hip Fracture Database (IHFD) standard compliance was compared from April to December 2017 and April to December 2018.

Results Two periods in 2017 and 2018 saw 121 and 122 hip fracture patients admitted, respectively. Mean time to admission to an orthopaedic ward in 2017 was $47 \pm 42.9 \mathrm{~h}$ and $33.3 \pm 42 \mathrm{~h}$ in $2018(P=0.5)$. Mean time to surgery in 2017 was $83.66 \pm 53.46 \mathrm{~h}$ and $39.11 \pm 10.84 \mathrm{~h}$ in $2018(p=0.026)$.

Conclusions Irish Hip Fracture Database Standards present a challenge to orthopaedic departments competing with other hospital specialties for access to beds and theatre space. The introduction of a GDPR-compliant social media messaging service has contributed to significantly reducing the time to surgery for these patients. Streamlining communication through messaging services has and continues to be vital to improving care for hip fracture patients, both in the healthcare environment and beyond.
\end{abstract}

Keywords Data protection $\cdot$ Healthcare $\cdot$ Hip fractures $\cdot$ Orthopaedics $\cdot$ Telemedicine $\cdot$ Trauma

\section{Introduction}

Major legal or regulation changes have always had a great impact on social and economic activities. Healthcare is one such activity enormously impacted by such changes. The General Data Protection Regulation (GDPR) has, and continues to have, implications on healthcare and the manner in which healthcare information is managed and shared.

Geoff Crozier-Shaw

gcrozshaw@hotmail.com

1 Department of Trauma \& Orthopaedic Surgery, Mater Misercordiae University Hospital, Eccles Street, Dublin, Ireland

2 National Orthopaedic Hospital Cappagh, Dublin, Ireland

3 Royal College of Surgeons in Ireland, Dublin, Ireland
GDPR came into effect in the European Union on the twenty-fifth of May 2018, making an immediate impact on businesses and services that involve the processing and storage of personalised data. In no other industry, or sector, is the use and storage of personal data more significant than in healthcare.

GDPR places greater obligations and responsibilities on how data processors collect, use, store, delete and protect data. It requires companies to be completely transparent with how they use, protect and safeguard personal data. Accountability must also be demonstrated in relation to data processing activities. Personal data is any information that can identify or relate to an individual or individuals. Names, dates of birth, medical record numbers, medical data, birthplaces, jobs and allergies are all examples of personal data. For obvious reasons, this has created a huge new challenge to healthcare activities operating within the European Union $[1,2]$. 
GDPR has already, and will continue to have, implications not only for general healthcare activities, but also for the increasingly important mechanisms of telemedicine.

Increasingly, telemedicine is becoming an important facet of modern medicine. The Irish Medical Council has defined telemedicine as "the delivery of healthcare services through information and communication technologies". It includes communication between doctors and patients, but also the exchange of information between doctors and other healthcare professionals [3].

With increasing pressure on healthcare resources, increasing legal regulation of working hours with the European Working Time Directive (EWTD) and increasing expectations from patients, telemedicine has proved to be an invaluable resource for stressed healthcare networks [4].

Acute stroke services have been delivered via telemedicine for some time [5]. Telemedicine communication allows rural communities access to healthcare that they would otherwise not receive; Australia and Bangladesh are particular examples where such services have been delivered [6,7]. Messaging services such as instant messaging applications enable rapid communication between healthcare professionals, resulting in reduced waiting times for patients and a speedier transit through the hospital system. It also allows for the sharing of clinical images, radiographic images and other details, which enable improved communication, ultimately improving patient outcomes. This does present medico-legal and regulatory challenges, of which GDPR is one. These messaging services have been shown to be both cheap and efficient $[8,9]$. Data security and ownership issues have raised concerns in relation to the use of privately owned messaging apps for communicating medical information. This has increased the demand for a healthcare-based social media messaging service that is GDPR compliant, secure and ethically run, whereby both clinicians and policy makers have confidence that data will be managed in a GDPRcompliant fashion.

MedxNote is a GDPR-compliant messaging app that uses data encryption and transport layer security (TLS) to ensure absolute privacy between clients and servers. Data is stored in a secure manner both while in transit and at rest. User management allows for control of those with access to data relayed using the service. Uses can be easily added and removed [10].

In 2007, the British Orthopaedic Association and British Geriatric Society published their "Blue Book", a care pathway for patients with fragility fractures. This outlined several key performance indicators (KPIs) for hip fracture care [11]. These were adopted as standards of care within the NHS and have also been adopted into KPIs for the Irish Hip Fracture Database (IHFD) [12]. It is through achievement of these KPIs that hip fracture care is optimised for these hip risk patients. These KPIs comprise six targets for hip fracture care, outlined in Table 1:

It has been shown that 30-day mortality in hip fracture patients has fallen from $11.9 \%$ in 2003 to $7.8 \%$ in 2011, since the introduction of the blue book standards in 2007 [13].

We aim to measure the impact improved communication via a GDPR-compliant messaging app can have on the time-dependent key performance indicators for hip fracture management of time to ward admission and time to surgery in a large, tertiary referral trauma unit.

This article was previously published as a meeting abstract from the Sylvester O'Halloran Surgical Symposium in March 2019. The abstract was published in the journal Mesentery and Peritoneum.

\section{Methods}

All stakeholders in IHFD Standards within our institution (orthopaedic surgeons, emergency physicians, bed managers and theatre nurse managers) were added to a dedicated group using the instant messaging platform MedxNote in April 2018.

The procedure for using the MedxNote platform for communication involved:

The patient arrives to the emergency department and is diagnosed with a proximal femur fracture on plain film radiograph.

A message is sent to the MedxNote group by the referring emergency physician following their diagnosis of a hip fracture.

The bed manager identifies a bed for transfer to the orthopaedic ward as soon as possible, usually a dedicated ringfenced "hip fracture bed".

Theatre managers and staff acknowledge the listing of the hip fracture case for theatre and identify the equipment needed for that afternoon, or the following morning.

A member of the on-call orthopaedic team urgently reviews the patient, contacts the anaesthetic doctor with any perioperative queries and organises an admission for operative management.

All relevant paperwork is completed to facilitate ward transfer within a 4-hour window, in compliance with Standard 1 (see Table 1) and to prioritise the patient

Table 1 Irish Hip Fracture Database standards of care for hip fracture management

\begin{tabular}{ll}
\hline Standard 1 & $\begin{array}{c}\text { Orthopaedic Ward Admission within } \\
\text { 4 hours }\end{array}$ \\
Standard 2 & Definitive Surgery within 48 hours \\
Standard 3 & Pressure Ulcer Prevention \\
Standard 4 & Orthogeriatric Care \\
Standard 5 & Bone Health Assessment \\
Standard 6 & Falls Assessment \\
\hline
\end{tabular}


for surgery within the 48-hour window, in compliance with Standard 2 (see Table 1).

Local IHFD data was reviewed to collect the two time critical perioperative Standards of "Time to Ward (less than 4 hours)" and "Time to Surgery (less than 48 hours)" within our trauma unit between April and December in 2018, since the introduction of MedxNote. A retrospective cohort from April to December 2017 was also assessed, so as to compare the standards from the time period before this encrypted messaging platform facilitated improved and more streamlined interdepartmental communication.

Statistics analyses were carried out using IBM SPSS Statistics for Windows, Version 24.0. Armonk, NY. Continuous data was assessed using Students' $t$ test and categorical data using two-tailed chi-squared test with Yates correction.

\section{Results}

Data gathered for the year 2017, from April to December, showed that one hundred and twenty-two patients $(n=122)$ were admitted and treated on the hip fracture pathway at our institution. This is comparable with the number from the same period in 2018, which was one hundred and twenty-one $(n=121)$. The time-dependent KPIs are outlined in Table 2.

The mean time to surgery was in $2017,83.66 \mathrm{~h}$ $( \pm 53.46)$, median of $60 \mathrm{~h}$. This compares with $39.11 \mathrm{~h}$ $( \pm 10.84)$ median $37 \mathrm{~h}$, in $2018(P=0.026$, significant, $t$ test).

The mean time from arrival to transfer to an orthopaedic ward was $47 \mathrm{~h}( \pm 42.9)$ in 2017 , compared with $33.3 \mathrm{~h}$ $( \pm 42)$ in 2018 ( $p=0.5$, not significant, $t$ test).

Compliance with Standard 1, the rate of admission to the orthopaedic ward within $4 \mathrm{~h}$ of arrival, was $1.6 \%$ in 2017, compared with $3.3 \%$ in 2018 ( $p=0.67$, not significant, chi-squared).

Compliance with Standard 2, the rate of surgery within $48 \mathrm{~h}$ from admission, stood at $53 \%(n=64)$ in 2017, compared with 73.5\% $(n=89)$ in $2018(p=0.0017$, significant, chi-squared).

Table 2 Time-dependent KPIs 2017 and 2018

\begin{tabular}{llll}
\hline & 2017 & 2018 & $P$ values \\
\hline Number of fractures & 122 & 121 & \\
Time to ward (hours) & $47 \pm 42.9$ & $33.3 \pm 42$ & 0.5 \\
Time to surgery (hours) & $83.66 \pm 53.46$ & $39.11 \pm 10.84$ & $P=0.026$ \\
\hline
\end{tabular}

\section{Discussion}

The challenges GDPR present to healthcare systems are significant. Telemedicine has great potential for improving and streamlining communication between doctors and other healthcare stakeholders. GDPR compliant messaging applications can improve and streamline these communications, potentially improving patient outcomes.

This study demonstrates that a GDPR-compliant messaging application, coupled with a communication innovation of generating a group with all hip fracture care stakeholders involved, can have significant improvement on improving time-dependent key performance indicators for hip fracture care. Time to surgery and time to orthopaedic wards were both significantly improved after introduction of this telemedicine modality.

Timely hip fracture care is essential to minimising morbidity and mortality associated with these fragility fractures. Studies have demonstrated that the thirty-day mortality rate for these injuries can be as high as $10 \%$, with reported 1-year mortality of 30\% [14].

The challenges presented by the Irish healthcare system in terms of access to beds are significant. Patients awaiting formal admission to beds from emergency departments are amongst the longest in Europe. This does make timely admission of patients to wards challenging. Through review of this department's compliance with the IHFD Standards, it has allowed assessment of where delays occur, with concerted efforts to offset these issues. These are discussed in the Limitations section below.

Statistically, studies have demonstrated that hip fractures undergo fixation after $48 \mathrm{~h}$ have significantly higher levels of mortality and morbidities. In a cohort study of 6036 hip fractures, the earlier surgical intervention groups of less than $24 \mathrm{~h}$ and 24 to $48 \mathrm{~h}$ exhibited a lower overall complication rate $(P=0.034)$ compared with the group waiting for surgery $>48 \mathrm{~h}$. Unadjusted mortality rates increased with delay to surgical intervention $(P=0.039)$ [15]. In a cohort analysis of 335 hip fractures, patients fast tracked to orthopaedic ward, time to surgery was mean $3 \mathrm{~h}$ shorter $88 \%$ underwent surgery within $24 \mathrm{~h}$ compared to $75 \%$ of those not fast tracked to the ward $(P=0.015)$. The overall probability for surgery within $24 \mathrm{~h}$ remained in favour of those fast-tracked to an orthopaedic ward [16]. A systematic review and meta-analysis showed that combined studies of 13,478 patients showed that earlier surgery was associated with a significant reduction in mortality (relative risk [RR] $0.81,95 \%$ confidence interval [CI] $0.68-0.96, p=0.01$ ). Unadjusted data indicated that earlier surgery also reduced in-hospital pneumonia (RR $0.59,95 \%$ CI $0.37-0.93, p=0.02$ ) and pressure sores (RR $0.48,95 \%$ CI $0.34-0.69, p<0.001$ ) [17]. 
The General Data Protection Regulation has changed the environment in relation to the processing and storage of personal information. This all pertains to personal information used in healthcare such as names, dates of birth, medical record numbers, as well as clinical information. Absolute privacy must be maintained and all data stored or used must be justifiable. Using social media for communication of any of these details is potentially fraught. However, the ownership of traditional social media and messaging apps could put healthcare practitioners into a difficult position in the context of the GDPR. Messaging applications such as Whatsapp do may not comply with GDPR standards due to concerns around ownership of these applications (Facebook in the case of Whatsapp) and their use for telemedicine should be discouraged [18].

As discussed above, telemedicine is becoming an increasingly commonplace and important tool for timely communication amongst healthcare practitioners, particularly doctors. The advent of GDPR compliant messaging apps such as MedxNote are paramount to maintaining the advantage that modern communication technology grants to healthcare practitioners while still protecting the personal data shared therein. These messaging applications are accessible in a manner of social media, in that multiple users can view the information communicated at the same time. This allows parallel dissemination of information amongst stakeholders rather than sequential transfer of information.

The recent Covid-19 pandemic has reinforced the important role that telemedicine can play in improving interdepartmental communication, but also in delivering healthcare remotely when appropriate [19-22].

It is through this study that we the authors have demonstrated the benefits these communication tools can have within a single trauma unit and it is important to consider their application in a broader context of communication within trauma networks.

\section{Limitations}

It is important to note that other factors were present which improved IHFD Standard compliance between the two 6-month cohorts. Communication improvements through the GDPR compliant messaging app were certainly part of this, but additional factors were also instrumental. Hospital management's allocation of a ring-fenced "hip fracture bed", to be kept empty only to be assigned to any hip fracture patient who presents to the emergency hospital, was instrumental in ensuring that patients were admitted and transferred to theatre in a timely fashion. The concerted effort on the part of both surgeons and anaesthetists to manage hip fractures in the most timely fashion is also an important contributory factor [23]. Errors in documenting the time of presentation to the emergency department, as opposed to the time of admission, through audit of the Irish Hip Fracture Database (IHFD), have been proven in the Irish setting. Strict documentation hygiene by the admitting team is paramount so as to allow accurate audit, given that national policies are based on the data produced by the IHFD [24]. Admission pathways and repatriation links have been established between hospitals and rehabilitation facilities, so as to reduce the time to surgery, as well as the overall length of stay [25].

\section{Conclusion}

Hip Fracture Blue Book Standards present a challenge to orthopaedic departments competing with other hospital specialties for access to beds and theatre space. The introduction of a GDPR-compliant social media messaging service has contributed to significantly reducing the time to surgery for these patients by improving interdepartmental communication.

Streamlining communication through messaging services have and continue to be vital to improving care for hip fracture patients, both in a pre-Covid-19 healthcare environment and beyond.

Author contribution All authors complied with standards and guidelines of ICMJE in relation to their contributions to the planning, data gathering, writing and review of this paper. No declarations or conflicts of interest needed. Audit-type activity and thus ethical approval were not needed or sought as per the Health Service Executive Guidelines on clinical audit.

\section{Declarations}

Ethics approval Audit activity, none requires as per HSE guidelines on clinical audit.

Conflict of interest The authors declare no competing interests.

\section{References}

1. Obligations of data controllers and processes under the GDPR. Citizens Information Board (2018) https://www.citizensinformation. ie/en/government_in_ireland/data_protection/obligations_under_ general_protection_regulation.html. Accessed 10th Sept 2020

2. Cornock M (2018) General Data Protection Regulation (GDPR) and implications for research. Maturitas 111:A1-A2. https://doi. org/10.1016/j.maturitas.2018.01.017

3. Guide to Professional Conduct and Ethics for Registered Medical Practitioners. Irish Medical Council (2016) P48. https:// www.medicalcouncil.ie/news-and-publications/reports/guide-toprofessional-conduct-and-ethics-for-registered-medical-practitionersamended-.pdf. Accessed 10th Sept 2020

4. Working Conditions- Working Time Directive (2003) European Union. Official Journal of the European Union: European 
Commission. https://ec.europa.eu/social/main.jsp?catId=706\& langId=en\&intPageId=205. Accessed 20th Sept 2020

5. Sinha K, Bettermann K (2019) Clinical outcomes of moderate to severe acute ischemic stroke in a telemedicine network. J Clin Neurosci 69:160-165. https://doi.org/10.1016/j.jocn.2019.08.003

6. St Clair M, Murtagh D (2019) Barriers to Telehealth uptake in rural, regional, remote Australia: what can be done to expand Telehealth access in remote areas? Stud Health Technol Inform 266:174-182. https://doi.org/10.3233/SHTI190791

7. Zobair KM, Sanzogni L, Sandhu K (2019) Expectations of telemedicine health service adoption in rural Bangladesh. Soc Sci Med 238:112485. https://doi.org/10.1016/j.socscimed.2019. 112485

8. Mars M, Scott RE (2016) WhatsApp in clinical practice: a literature review. Stud Health Technol Inform 231:82-90 (PMID: 27782019)

9. Morris C, Scott RE, Mars M (2018) Security and other ethical concerns of instant messaging in Healthcare. Stud Health Technol Inform 254:77-85. https://doi.org/10.1177/1357633X19873233

10. MedxNote Limited (2019) https://medxnote.com/why-medxnote. Accessed 20th Sept 2020

11. Care of Patients with Fragility Fracture (2007) (2007) British Orthopaedic Association and British Geriatric Society. https:// www.bgs.org.uk/sites/default/files/content/attachment/2018-0502/Blue\%20Book\%20on\%20fragility\%20fracture\%20care.pdf. Accessed 20th Sept 2020

12. Irish Hip Fracture Database National Report 2017 (2017) National Office of Clinical Audit (NOCA) 2017. https://www.noca.ie/ documents/ihfd-national-report-2017\#: :text=This\%20fifth\% 20IHFD \%20report\%20details,all\%20hip\%20fracture\%20cases\% 20nationally. Accessed 20th Sept 2020

13. Wilson H (2017) Orthogeriatrics in hip fracture. Open Orthop J 11:1181-1189. https://doi.org/10.2174/1874325001711011181

14. Parker MJ, Anand JK (1991) What is the true mortality of hip fractures? Public Health 105(6):443-446. https://doi.org/10.1016/ s0033-3506(05)80614-6

15. Alvi HM, Thompson RM, Krishnan V et al (2018) Time-to-surgery for definitive fixation of hip fractures: a look at outcomes based upon delay. Am J Orthop (Belle Mead NJ) 2018(47):9. https://doi. org/10.12788/ajo.2018.0071

16. Eriksson M, Kelly-Pettersson P, Stark A et al (2012) "Straight to bed" for hip-fracture patients: a prospective observational cohort study of two fast-track systems in 415 hips. Injury 43(12):21262131. https://doi.org/10.1016/j.injury.2012.05.017

17. Simunovic N, Devereaux PJ, Sprague A et al (2010) Effect of early surgery after hip fracture on mortality and complications: systematic review and meta-analysis. CMAJ 182(15):1609-1616. https://doi.org/10.1503/cmaj.092220

18. Masoni M, Guelfi MR (2020) WhatsApp and other messaging apps in medicine: opportunities and risks. Intern Emerg Med 15(2):171-173. https://doi.org/10.1007/s11739-020-02292-5

19. Greenhalgh T, Wherton J, Shaw S et al (2020) Video consultations for Covid-19. BMJ 368:m998. https://doi.org/10.1136/bmj.m998

20. Hollander JE, Carr BG (2020) Virtually Perfect? Telemedicine for Covid-19. N Engl J Med. https://doi.org/10.1056/NEJMp2003539

21. Smith AC, Thomas E, Snoswell CL et al (2019) Telehealth for global emergencies: Implications for coronavirus disease (COVID-19). J Telemed Telecare 2020 26(5):309-313. https:// doi.org/10.1177/1357633X20916567

22. Coronavirus disease (2019) World Health Organisation (WHO). www.who.org: World Health Organization 2020. https://www. who.int/health-topics/coronavirus\#tab=tab_1. Accessed 20th Sept 2020

23. Mullins B, Akehurst H, Slattery D et al (2018) Should surgery be delayed in patients taking direct oral anticoagulants who suffer a hip fracture? A retrospective, case-controlled observational study at a UK major trauma centre. BMJ Open 8(4):e020625. https:// doi.org/10.1136/bmjopen-2017-020625

24. Hughes AJ, Hennessy O, Brennan L et al (2019) How accurate is the data provided to the Irish hip fracture database? Ir J Med Sci 188(1):13-18. https://doi.org/10.1007/s11845-018-1810-5

25. Hughes AJ, Brent L, Biesma R et al (2019) The effect of indirect admission via hospital transfer on hip fracture patients in Ireland. Ir J Med Sci 188(2):517-524. https://doi.org/10.1007/ s11845-018-1854-6 